\title{
Gram-positive Staphylococcus aureus LTA promotes distinct memory-like effects in murine bone marrow neutrophils
}

\author{
Trim Lajqi ${ }^{1}$, David Frommhold ${ }^{2}$, Maylis Braun ${ }^{1}$, Simon Alexander Kranig ${ }^{1}$, Johannes Pöschl ${ }^{1}$ and \\ Hannes Hudalla ${ }^{1}$
}

\begin{abstract}
${ }^{1}$ Department of Neonatology, Heidelberg University Children's Hospital, 69120 Heidelberg, Germany

${ }^{2}$ Klinik für Kinderheilkunde und Jugendmedizin, 87700 Memmingen, Germany Correspondence should be addressed to Hannes Hudalla; Hannes.Hudalla@med.uniheidelberg.de
\end{abstract}

\begin{abstract}
Neutrophils as innate immune cells primarily act as first responders in acute infection and directly maintain inflammatory responses. However, a growing body of evidence suggests that neutrophils also bear the potential to mediate chronic inflammation by exhibiting memory-like features. We recently showed that priming by serial doses of lipopolysaccharide (LPS) from gramnegative bacteria can trigger opposing memory-like responses (exaggerated inflammation, i.e. trained sensitivity or suppression of inflammation, i.e. tolerance) depending on the LPS-dose. We now asked whether this observation could also hold true for lipoteichoic acid (LTA) from gram-positive S. aureus. We found comparable effects of LTA on neutrophil priming as seen for LPS. Lowdose (1 $\mathrm{ng} / \mathrm{mL})$ LTA-priming promoted increased production of proinflammatory mediators (i.e., TNF- $\alpha$, IL-6, ROS), whereas high-dose $(10 \mu \mathrm{g} / \mathrm{mL})$ results in contrary reactions supporting anti-inflammatory responses by increased IL-10 and declined pro-inflammatory capacity. In vitro neutrophil recruitment was similarly regulated by LTA -priming. Investigation of signalling patterns revealed TLR2/MyD88-mediated regulation of NFKB-p65 through intermediate PI3Ks/MAPK. Collectively, our data suggest a previously unknown capacity of neutrophils to be differentially primed by varying doses of LTA, endorsing memory-like features in neutrophils.
\end{abstract}

Keywords: neutrophils; priming; innate immunity; immune-memory

\section{Introduction}

Neutrophils are the most abundant type of polymorphonuclear (PMN) leukocytes and among the first innate immune cells entering the site of infection [1,2]. Formerly, neutrophils have been considered as evolutionary primitive and functionally restricted to pro-inflammatory properties during acute infections [3-5]. They continuously survey for any microbial infections and act against them engaging an armory of antimicrobial agents such as cytokines and chemokines, reactive oxygen species (ROS), enzymes (i.e., defensins, cathepsins, lysozymes) as well as they improve their recruitment cascade to encounter the invading pathogens [4-7]. Once released into the circulation, neutrophils have a short life-span of around $48 \mathrm{~h}$ after which they get cleared by the liver, spleen or bone marrow - a process regulated by CXC-chemokine receptor 4 (CXCR4), or they get phagocytosed by macrophages [8-12]. Even 
though neutrophils are too short-lived to primarily shape and regulate long-term responses, recent evidence also from out lab demonstrates their potential to at least induce distinct memory-like inflammatory responses [13-16].

Innate immune cells can sense different conserved microbial structures termed pathogen-associated molecular patterns (PAMPs) by their germline-encoded pattern recognition receptors (PRRs) [17]. Activation of PRRs results in downstream signalling events culminating in the production of inflammatory mediators [17-20]. For a long time, innate immune cells have been considered evolutionary primitive due to a lack of immunological memory as an exclusive hallmark of adaptive (acquired) immunity. A rising number of studies suggest however, that innate immune cells (i.e., monocytes, macrophages, microglia, natural killer (NK) cells) as well as tissue-resident stem cells possess a memorylike capacity during secondary infections [21-26]. Netea and colleagues were among the first to discover that innate immune cells primed by $\beta$ glucan or bacillus Calmette-Guerin (BCG) after a secondary challenge triggered the release of pro-inflammatory mediators, whereas cells primed by the principal outer membrane component of gram-negative bacteria, lipopolysaccharide (LPS), were marked by increased antiinflammatory features (i.e., IL-10) and suppressed pro-inflammatory reactions [21,24,27-32]. These findings concluded a PAMP-specific induction of the opposing memory-like inflammatory responses. Later on, several findings disclosed the pathogen dose as well as the maturation state as crucial determinants shaping the induction of these immune memory in innate immune cells [24,28,33-37]. Epigenetic reprogramming and changes in cell metabolism have been identified to orchestrate both types of memory-like responses [29,38-41].

Memory-like ques of neutrophils have been reported previously, showing that the recruitment and capacity to neutralize pathogens can be primed by IL-8, TNF- $\alpha$, or microbiome-derived metabolites [42-46]. Moreover, primed neutrophils may drive anti-tumoral reactions as well as pronounced antimicrobial activity upon a secondary exposure $[14,47]$. Recent work from our group showed that LPS-primed neutrophils in vitro promote opposing memory-like inflammatory responses in a dosedependent manner characterized by altered cytokine patterns as well as ROS production resulting with distinct changes in migratory as well as phagocytic activities [13]. It is not known however, whether similar patterns also exist for cell components of gram-positive bacteria, especially for lipoteichoic acid (LTA). LTA is the main cell membrane constituent of gram-positive bacteria and a recognized immunomodulator that plays an important role in bacterial growth and virulence [48]. LTA is a strong activator of immune cells, triggering the release of inflammatory mediators which may result in septic shock and multiorgan failure $[49,50]$. However, the effects of LTA on the induction of memory-like responses remain elusive.

The current work describes the role of LTA-priming promoting distinct memory-like inflammatory reactions, trained sensitivity and tolerance in a dose-dependent manner in murine bone marrow neutrophils in vitro. In vitro, low-dose LTA-primed neutrophils with a secondary LPS stimulus exhibit elevated levels of pro-inflammatory mediators (trained sensitivity) outlined by elevated TNF- $\alpha$, IL-6, ROS and IL-1 $\beta$. In contrast, high-dose LTA-primed neutrophils trigger an immune-suppressive phenotype characterized by diminished pro- 
inflammatory responses and high IL-10 production. Further, trained neutrophils show enhanced migration, whereas the opposite effect can be seen for tolerant neutrophils in vitro. This study further expands our previous findings on the role of PAMPs in priming neutrophil function. Both LPS and LTA as integral components of bacteria can induce inflammatory and anti-inflammatory phenotypes in neutrophils depending on sequence of exposure and dose. Our hypothesis that neutrophils have the capacity to be primed and exhibit a certain level of immune-plasticity is supported by the current study.

\section{Materials and Methods}

\subsection{Isolation of murine bone marrow neutrophils}

Murine bone marrow neutrophils were isolated from 3-6 months old C57Bl/6J locally inbred mice. All mice were housed in a central animal facility with standard care (12- hour day cycle, standard nutrition an water). All experiments were performed in accordance with the guidelines from Directive 2010/63/EU of the EU Parliament on the protection of animals used for scientific purposes and approved by the Regierungspräsidium Karlsruhe, Germany (Az T-02/20).

Tibias and femurs were flushed to isolate bone marrow and neutrophils were purified by discontinuous Percoll gradient (\#17-089102, GE Healthcare) as previously described [51-54]. At the 64\%/81\% interface neutrophils were collected, followed by a single washing step with phosphate buffered saline (PBS). Afterwards cells were kept in culture medium [RPMI-1640 (\#R8758, Sigma-Aldrich) $+10 \%$ fetal bovine serum (FBS, \#PB-FCS-EU-0500, PeloBiotech; heat-inactivated and sterilefiltered) $+1 \%$ amphotericin $\mathrm{B}+1 \%$ penicillin/streptomycin)]. Cell viability was regularly monitored by the trypan blue (AppliChem, Darmstadt, Germany) exclusion (viability $>95 \%$ ). In line with previous reports, $>98 \%$ of all cells were neutrophils with this method $[51,54]$.

\subsection{Neutrophil stimulation procedure}

1.000.000 cells/well were treated immediately after isolation as published before and shown in Figure 1A [13]. Cells were challenged twice, first by priming with increasing doses of $S$. aureus LTA $(100 \mathrm{pg} / \mathrm{mL}$ - $10 \mu \mathrm{g} / \mathrm{mL}$ ) (InvivoGen (\#tlrl-pslta, Toulouse, France) for 45 minutes at $37^{\circ} \mathrm{C}$ and $5 \% \mathrm{CO}_{2}$, followed by two medium changes. On day two, neutrophils we re-stimulated with the standard dose of $100 \mathrm{ng} / \mathrm{ml} \mathrm{E.} \mathrm{coli}$ 055:B5 LPS (InvivoGen (\#tlrl-pb5lps, Toulouse, France) and were left at $37^{\circ} \mathrm{C}$ and $5 \% \mathrm{CO}_{2}$ for $4 \mathrm{~h}$. The supernatant, protein lysates and RNS were collected. Unstimulated cells (US) and unprimed cells (only exposed to the secondary stimulus with LPS) served as controls.

\subsection{Antibodies}

All primary antibodies were obtained from Cell Signaling (USA) [TLR2 (\#13744), p44/42 MAPK (ERK1/2) (\#9107), phospho-p44/42 MAPK (ERK1/2) (Thr202/Tyr204) (\#9106), Akt (\#9272), phospho-Akt (Ser473) (\#9271), MyD88 (\#4283)]. $\beta$-actin was used to normalize (\#A5441, Sigma Aldrich, St. Louis, USA). As secondary HRP-antibodies we used antirabbit (\#111-035-144) and anti-mouse (\#115-035-166) (Dianova, Hamburg, Germany).

\subsection{Western blotting}


Neutrophil lysis was performed on ice using RIPA buffer $(50 \mathrm{mM}$ Tris/HCl pH 8; $150 \mathrm{mM} \mathrm{NaCl}, 1 \%$ (v/v) NP-40, 0.1\% (w/v) SDS, 0.5\% (v/v) Na-deoxycholate, $1 \mathrm{mg} / \mathrm{mL}$ Pepstatin A, $100 \mathrm{mg} / \mathrm{mL}$ Pefa-Block, $1 \mathrm{mg} / \mathrm{mL}$ Leupeptin, $10 \mathrm{mM}$ sodium vanadate). After centrifugation $(13.500 \mathrm{x} \mathrm{g}, 30$ $\left.\min , 4^{\circ} \mathrm{C}\right), 5 x$ protein sample buffer ( $5 \%$ SDS, $25 \% \beta$-mercaptoethanol, $33 \%$ glycerol, $83 \mathrm{mM}$ Tris- $\mathrm{HCl} \mathrm{pH} 6.8,0.1 \mathrm{mg} / \mathrm{mL}$ bromophenol blue) was added and the mix was heated at $95^{\circ} \mathrm{C}$ for $5 \mathrm{~min}$. Samples were separated on a $10 \%$ polyacrylamide gel, followed by transfer to a PVDF membrane. Protein bands were detected after antibody incubation using a ChemiDoc XRS+ system (Bio-Rad Laboratories, USA). Blots were quantified using Image Lab software (version 6.0.1, Bio-Rad Laboratories, USA).

\subsection{Protein concentration measurements}

Protein concentrations were measured using the Pierce ${ }^{\mathrm{TM}} 660 \mathrm{~nm}$ Kit (\#22662, Thermo Fisher Scientific, Waltham, MA, USA) following manufacturer's instructions. Ionic detergent compatibility reagent (IDCR) (\#22663, Thermo Fischer Scientific, Waltham, MA, USA) was used in order to increase the detergent compatibility and reduce interference. In brief, assay reagent containing ionic detergent compatibility reagent (IDCR; \#22663, Thermo Fischer Scientific, Waltham, MA, USA) was added to standards, samples and blanks, which were previously pipetted on a 96-well plate. Absorbance was measured at $660 \mathrm{~nm}$ and protein concentration was then calculated according to manufacturer's instructions.

\subsection{Quantification of cytokine and chemokine production}

Commercially available ELISA kits were used as previously described [13,28]. TNF- $\alpha$, IL-6 and IL-10 ELISAs were purchased BioLegend (respective order \# 430901, 431301, 431411, San Diego, CA, USA), whereas CXCL1/KC was obtained from R\&D Systems (\#DY453-05, Minneapolis, MN, USA). Absorbance was measured at 450/570 nm. The total sample protein concentration was used to normalized chemokine and cytokine concentrations (expressed as $\mathrm{pg} / \mu \mathrm{g}$ protein)

\subsection{ROS production}

ROS production in murine bone marrow neutrophils was assessed using the DCFDA/H2DCFDA Assay Kit (\#ab113851, Abcam, Cambridge, UK) following manufacturer's instructions as described previously [13]. In brief, neutrophils were seeded (100.000 cells/well) into black clear bottom 96-well plates and treated according to experimental protocol. After removal of medium, $20 \mu \mathrm{M}$ DCFDA solution was added for $30 \mathrm{~min}$ at $37^{\circ} \mathrm{C}$. After two washing steps, cells were resuspended in supplementary buffer provided in the kit. Intracellular ROS was quantified by fluorescence spectroscopy at 485/ $535 \mathrm{~nm}$ using a Wallac Victor3 1420 plate reader (PerkinElmer, Turku, Finland).

\subsection{In vitro transmigration assay}

Transmigration of neutrophils was assessed using an assay kit (\#CBA-104, Cell Biolabs, CA, USA) as described previously and according to manufacturer's instructions [13]. Neutrophils from respective experimental conditions were placed into the 96-well membrane chamber, which was then placed in the feeder tray containing $10 \%$ FCS-supplemented medium for $5 \mathrm{~h}$ at $37^{\circ} \mathrm{C}$ and $5 \% \mathrm{CO}_{2}$. Cells were 
dislodged using the kit cell detachment solution for $30 \mathrm{~min}$. $150 \mu \mathrm{L}$ of cell solution were transferred to a new 96-well plate, and incubated with 50 $\mu \mathrm{L} 4 \mathrm{x}$ lysis buffer/CyQuant GR dye solution for $20 \mathrm{~min}$ at room temperature. Fluorescence was measured with the same settings as for ROS production measurements using the Wallac Victor3 plate reader (results expressed as relative fluorescence units, RFU).

\subsection{Cell viability and cytotoxicity}

MTT assay was used to determine cell viability. Neutrophils (200.000 cells/well) were treated as per experimental protocol in a 96-well plate. After the addition of $10 \mu \mathrm{L} 0,5 \mathrm{mg} / \mathrm{mL}$ MTT per well, samples were incubated for $4 \mathrm{~h}$, solubilization solution was added followed by incubation overnight all at $37^{\circ} \mathrm{C}$ and $5 \% \mathrm{CO}_{2}$. Absorbance was measured at $570 \mathrm{~nm}$. Data are expressed as relative viability compared to unprimed (UP) (Supplementary Figure 1A). Cytotoxicity of the experimental treatment was assessed using a cell cytotoxicity assay kit (colorimetric; \#ab112118, Abcam, Cambridge, UK) according to manufacturer's instructions as described previously [13]. The absorbance was measured at $570 \mathrm{~nm}$ and data are expressed as relative cytotoxicity compared to unprimed (UP) (Supplementary Figure 1B).

\subsection{RNA isolation and real-time PCR}

RNA extraction was performed using QIAzol (\#79306, Qiagen, Hilden, Germany) as described before [55]. RNA concentration and quality were assessed by Nanodrop (Novix, DE, USA) measurements. cDNA synthesis was performed using a kit from Thermo Fisher (\#K1612, Waltham, MA, USA) and RT qPCR was run on a StepOnePlusTM RT PCR System (Applied Biosystems, USA). Gene expression was normalized to GAPDH expression as an internal house-keeping control and deloged as $2^{-\Delta \Delta C_{T}}$ [56]. Primer paris are listed below:

\begin{tabular}{|c|c|c|}
\hline Gene & forward primer & Reverse primer \\
\hline IL-1 $\beta$ & 5'-GGCAGGCAGTATCACTCATT-3' & 5'-AAGGTGCTCATGTCCTCAT-3' \\
\hline IL-10 & 5'-ACCAGCTGGACAACATACTGC-3' & 5'-TCACTCTTCACСТGCTCCACT-3' \\
\hline p65 & 5'-CTTCСTCAGCCATGGTACCTCT-3' & 5'-CAAGTCTTCATCAGCATCAAACTG-3' \\
\hline CD11a & 5'-AGATCGAGTCCGGACCCACAG-3' & 5'-GGCAGTGATAGAGGCCTCCCG-3' \\
\hline GAPDH & 5'-CATGGCCTTCCGTGTTTCCTA-3' & 5'-CCTGCTTCACCACCTTCTTGAT-3' \\
\hline
\end{tabular}

\subsection{Statistical analysis}

GraphPad Prism (version 8.0.2, GraphPad Software, CA, USA) was used for graphical display. All statistics were carried out using SigmaPlot (version 12.0, Systat Software GmbH, Erkrath, Germany). Shapiro-Wilk normality test was run prior to statistical analysis. Multi-group comparisons were made by one-way ANOVA followed by Holm-Sidak posthoc analysis. Significance was set at $p<0.05$. Data are presented both as individual data points and mean + SEM.

\section{Results}

3.1. LTA-priming induces dose-dependent inflammatory responses in murine bone marrow neutrophils

To better understand the LTA-mediated inflammatory capacity of neutrophils, we quantified the inflammatory output (TNF- $\alpha$ and IL-6 production) in response to rising concentrations of LTA (Figure 1B, C). 
After re-challenge with a fixed dose of $100 \mathrm{ng} / \mathrm{mL}$ LPS, we found increased levels of cytokine production in low-dose $(1 \mathrm{ng} / \mathrm{mL})$ LTAprimed neutrophils, whereas priming with $\geq 1 \mu \mathrm{g} / \mathrm{mL}$ LTA diminished levels of TNF- $\alpha$ and IL-6 production (Figure 1D, E).

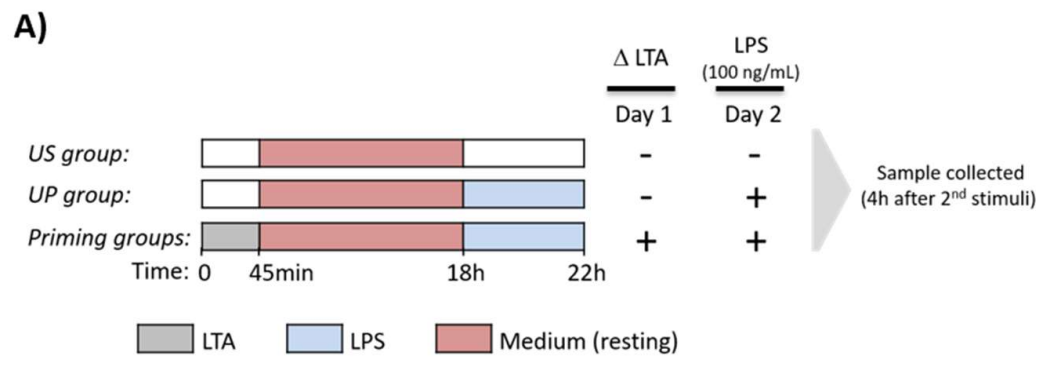

Single-stimulation (priming)

B)

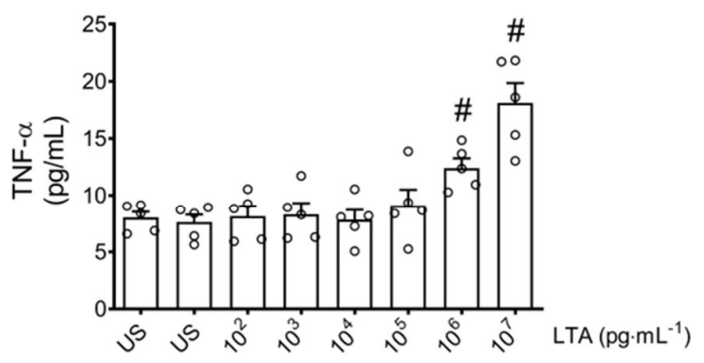

Memory-like features

D)

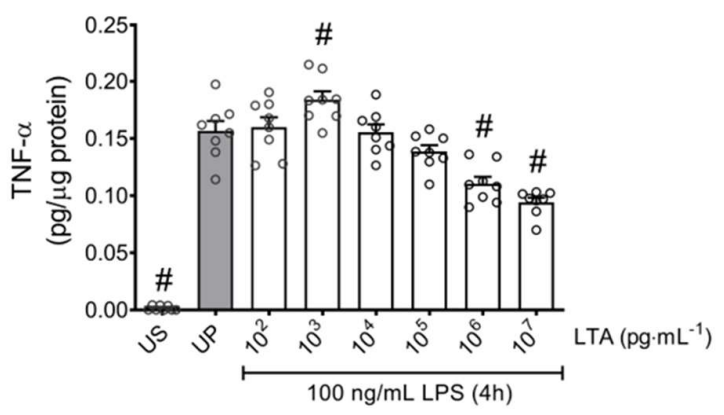

C)

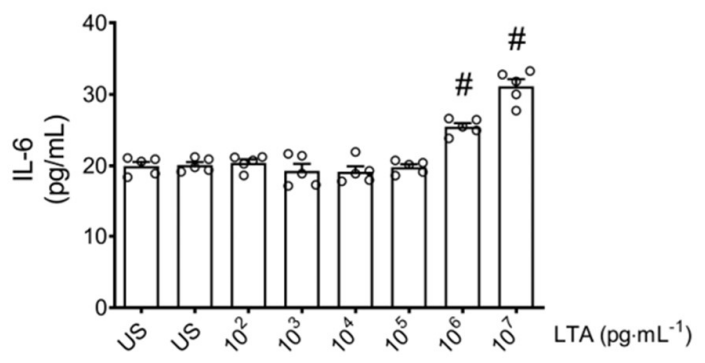

E)

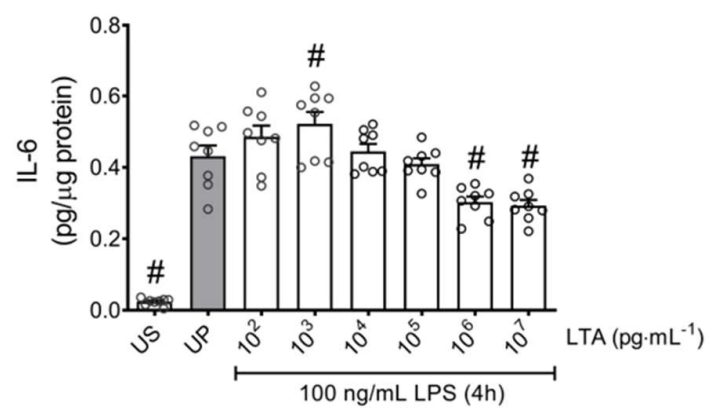

Figure 1. Role of LTA-priming on the production of pro-inflammatory cytokines in murine neutrophils. (A) Experimental outline with two stimuli for the induction of memory-like features in murine bone marrow neutrophils. (B) TNF- $\alpha(n=5)$ and (C) IL-6 ( $n=5)$ as pro-inflammatory cytokine assayed by ELISA in supernatants collected from LTA-primed (single-stimulated) murine bone marrow neutrophils. Memory-like inflammatory reactions (D: TNF- $\alpha, n=8$; E: IL-6, $n=8$ ) in neutrophils primed by escalating doses of LTA after a second challenge with 100ng/ml LPS. assayed by ELISA (normalized to total protein concentration). Individual data points and mean + SEM are shown. \# depicts significant differences to the unstimulated condition (US) (B, C) or the unprimed condition (UP, gray column) (D, E).

We then analyzed the production of other pro-inflammatory mediators like ROS and IL- $1 \beta$, as well as anti-inflammatory IL-10 cytokine production and its expression (Figure 2). We found that both ROS and IL-1 $\beta$ are significantly increased in low-dose $(1 \mathrm{ng} / \mathrm{mL})$ LTAprimed neutrophils displaying trained sensitivity reactions, whereas 
priming by a higher dose $(10 \mu \mathrm{g} / \mathrm{mL})$ LTA-primed cells showed diminished levels after LPS challenge revealing a level of immune tolerance (Figure 2A, B). In contrast, IL-10 production was not affected by priming with low doses of LTA, however priming with high doses of LTA led to increased levels of IL-10 (Figure 2C, D).
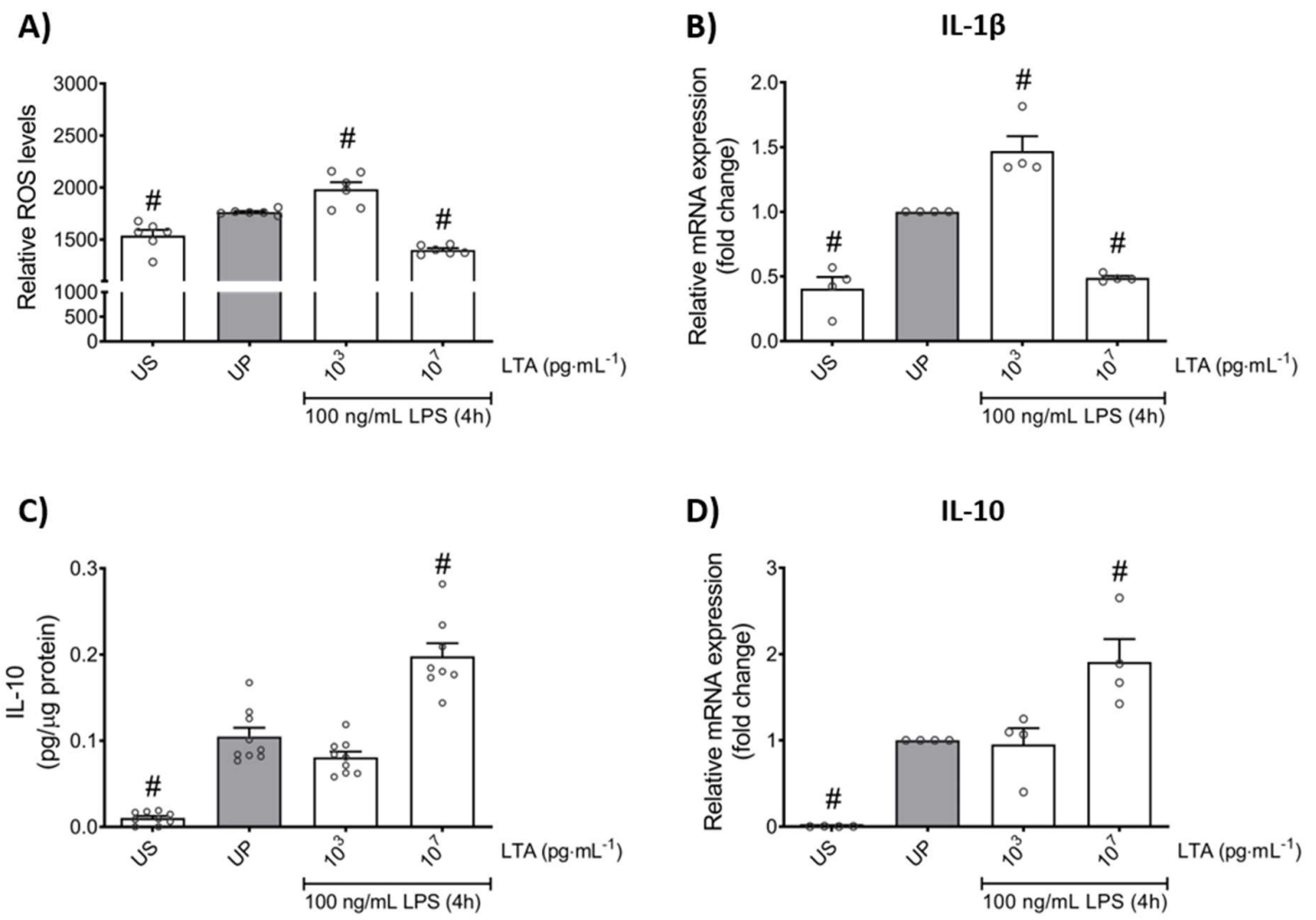

Figure 2. LTA-priming effects on pro- and anti-inflammatory mediators in murine bone marrow neutrophils. LTA-primed neutrophils $(1 \mathrm{ng} / \mathrm{mL}=$ low-dose; $10 \mu \mathrm{g} / \mathrm{mL}=$ high-dose $)$ were re-stimulated on day 2 with $100 \mathrm{ng} / \mathrm{mL}$ LPS as described above. The levels of (A) ROS ( $\mathrm{n}=6$ ) were measured by DCFDA assay and (C) IL-10 ( $\mathrm{n}=8-9)$ cytokine production assessed by ELISA (normalized to total protein concentration), whereas gene expression of (B) IL-1 $\beta(n=4)$ and (D) IL-10 $(n=4)$ was analyzed by RT-PCR and expression normalized to unprimed, UP, set as 1. Individual data points and mean + SEM are shown. \# depicts significant differences to unprimed condition (UP, gray column). $\mathrm{p}<0.05$ was considered statistically significant.

Cell viability was not affected during the experimental procedure as verified by viability and cytotoxicity assays (Supplementary Figure 1). Taken together our data show that LTA priming of murine bone marrow neutrophils may induce opposing inflammatory responses upon a second challenge by LPS, where low-dose priming promotes trained sensitivity and high-dose priming drives tolerance reactions.

\subsection{TLR2/PI3K/MAPK activation of $p 65$ regulates LTA-priming effects}

Next, we examined the potential signalling proteins which could help understand these antagonistic inflammatory reactions upon LTApriming. Trained sensitivity is characterized by enhanced protein expression of TLR2/MyD88/p65, distinct from the tolerant state of neutrophils outlined by its downregulation (Figure 3A, B, E). In line with this observation, activation of protein kinase $\mathrm{B}(\mathrm{Akt})$ as a key downstream mediator of phosphoinositide 3-kinases (PI3Ks), as well as extracellular 
signal-regulated kinase (ERK) $1 / 2$ as an important member of the mitogen-activated protein kinase (MAPK)-mediated pro-inflammatory pathway were similarly regulated in murine bone marrow neutrophils (Figure 3C, D). Trained neutrophils exhibited enhanced expression levels of Akt/ Erk1/2, distinct from tolerant neutrophils that showed diminished protein expression of Akt.

A)
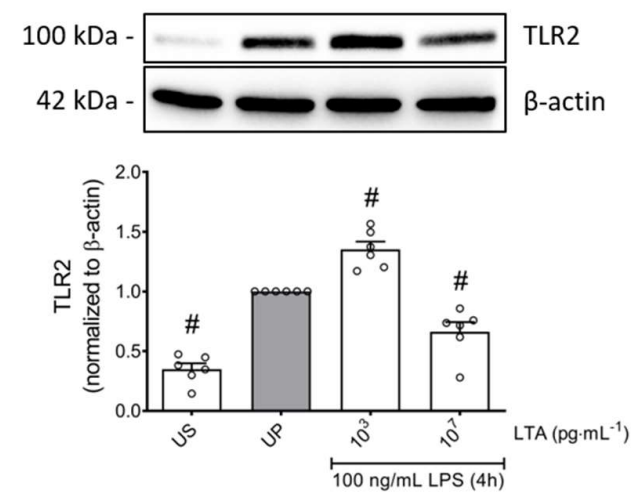

C)
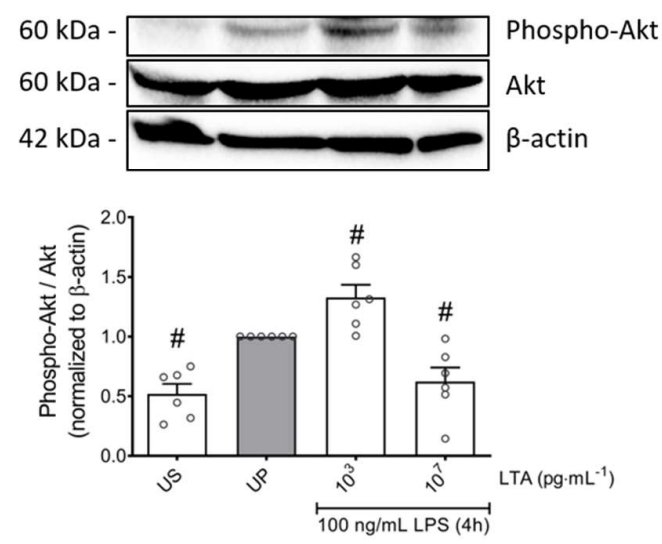

E)

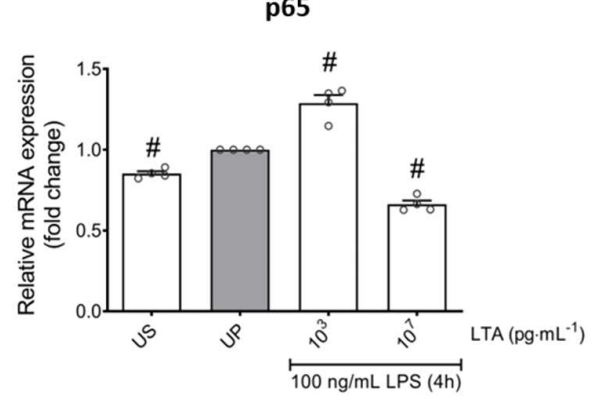

B)

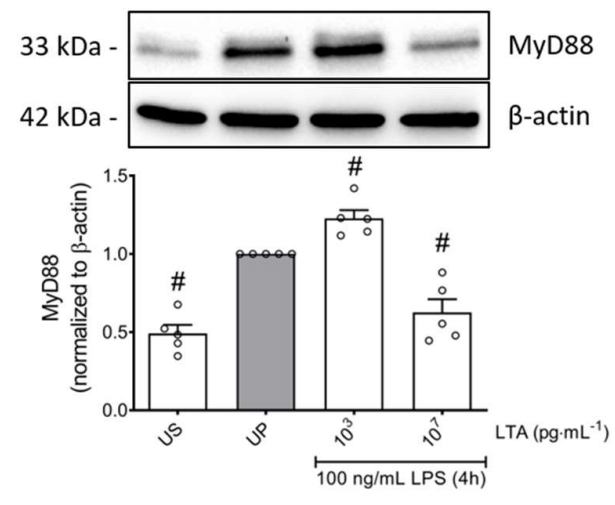

D)

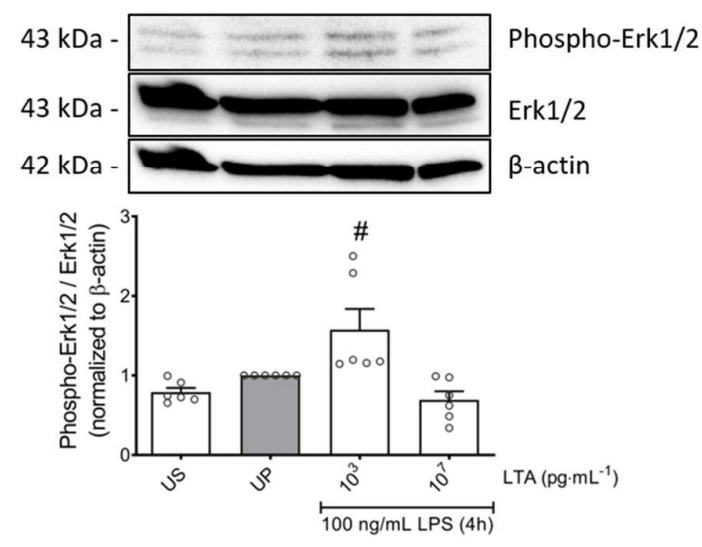

Figure 3. LTA-priming alters TLR2/PI3K/MAPK/p65 signalling patterns in murine bone marrow neutrophils. LTA-primed neutrophils $(1 \mathrm{ng} / \mathrm{mL}=$ low-dose; $10 \mu \mathrm{g} / \mathrm{mL}=$ high-dose $)$ were re-stimulated on day 2 with $100 \mathrm{ng} / \mathrm{mL}$ LPS as described above. Lysates were collected 4 h after LPS re-challenge and the protein expression of (A) TLR2 (n=6), (B) MyD88 (n=5), (C) phospho-Akt (n=6) and (D) phosphoErk1/2 $(n=6)$ were analyzed by Western blotting and quantified (unprimed neutrophils assigned as 1.0). Gene expression of p65 (E, n=4) was assessed by RT-PCR and normalized to unprimed, UP, set as 1 . Individual data points and mean + SEM are shown. \# depicts significant differences to unprimed condition (UP, gray column). $\mathrm{p}<0.05$ was considered statistically significant. 
Taken together, our data show that the two opposing states of primed neutrophils correlate with distinct regulation of NFkB-p65 by TLR2/PI3K/MAPK.

\subsection{LTA-primed inflammatory responses reshape the migratory capacity of murine bone marrow neutrophils in vitro}

In order to validate that the cellular processes observed have meaning in regard to cellular immune function, we assessed neutrophil transmigration in vitro. Murine bone marrow neutrophils primed by 1 ng/mL LTA display enhanced migratory effects characterized by increased production of C-X-C motif ligand 1 (CXCL1) chemokine as one of the crucial ligands required for neutrophil trans-endothelial migration (Figure 4A, B). Antagonistic features were found in high-dose $(10 \mu \mathrm{g} / \mathrm{mL})$ LTA-primed neutrophils, where both in vitro migration and CXCL1 production were dampened (Figure 4A, B). In parallel, we analyzed the expression of CD11a as an integral component of neutrophil recruitment and found comparable dose-effects (Figure 4C). Our findings suggest that the cellular processes of dose-dependent neutrophil priming neutrophils correlate with cellular function.

A)

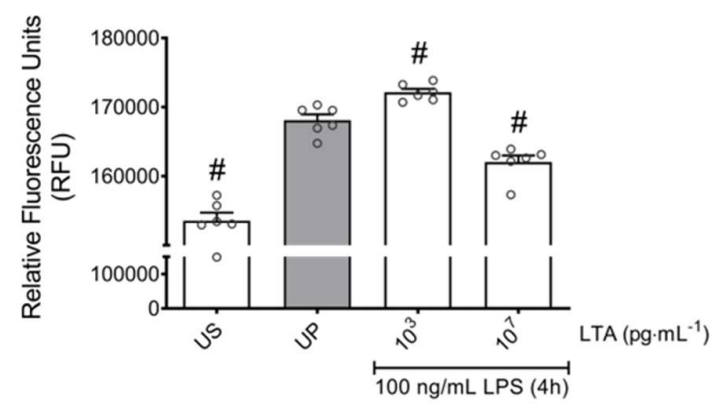

C) CD11a

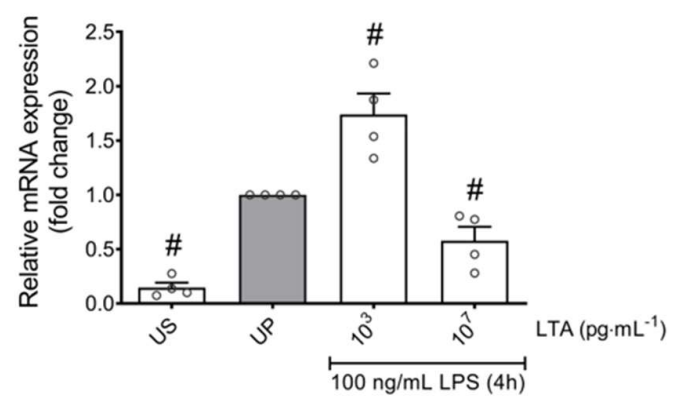

B)

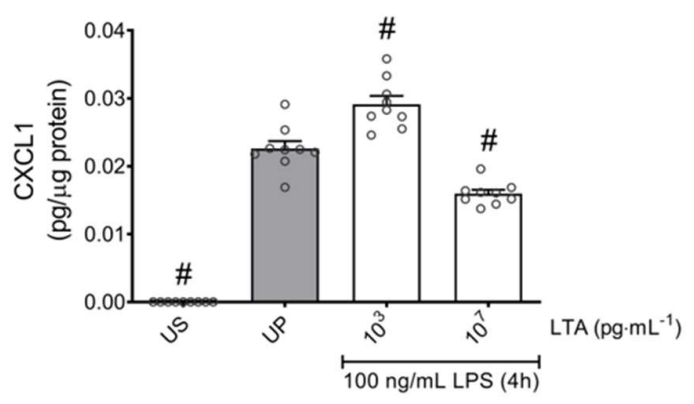

Figure 4. LTA-priming reshapes the transmigrational potential of murine bone marrow neutrophils. LTA-primed neutrophils $(1 \mathrm{ng} / \mathrm{mL}=$ low-dose; $10 \mu \mathrm{g} / \mathrm{mL}=$ high-dose $)$ were re-stimulated on day 2 with $100 \mathrm{ng} / \mathrm{mL}$ LPS as described above. (A) Migration $(\mathrm{n}=6)$ of murine neutrophils was assessed by migration assay. Chemokine production of $(B)$ CXCL1 $(n=9)$ was measured by ELISA (normalized to total protein concentration), whereas gene expression of $(C) C D 11 a(n=4)$ was assessed by RT-PCR and normalized to unprimed, UP, set as 1 . Individual data points and mean + SEM are shown. \# depicts significant differences to unprimed condition (UP, gray column). $\mathrm{p}<0.05$ was considered statistically significant.

\section{Discussion}


In recent years the dichotomy concept of innate and adaptive immunity witnessed a paradigm shift. Innate immune cells like monocytes, macrophages, NK cells and microglia are now recognized to exhibit non-specific memory-like (adaptive) reactions in response to reinfections. Both memory-like states of the innate immune cells, training as well as tolerance, are accompanied by epigenetic modifications occurring in $\mathrm{H} 3$ or $\mathrm{H} 4$ histones and regulated by different immunometabolic modulations promoting either an increased responsiveness or diminished responses against secondary infections [29,32,39-41,57-59]. Different studies revealed pathogen-specificity, dose-dependency, magnitude of priming as well as the maturation state as crucial factors affecting the development of memory-like responses in innate immune cells $[23,24,27,28,31-33,60]$. However, there are still many fundamental questions to be addressed, for example which spectrum of bacterial, fungal and viral components or other stressing agents may trigger such memory-like responses [61,62].

Terminally differentiated neutrophils represent an essential part of the innate immune system involved in early defense against infectious stressors [8,63]. They possess a variety of antimicrobial agents like reactive oxygen species (ROS), pro-inflammatory cytokines (i.e., TNF- $\alpha$, IL-6, IL-1 $\beta$ ), chemokines (i.e., CXCL1, MCP-1) and hydrolytic enzymes to protect against infectious agents, as well as anti-inflammatory mediators such as IL-10 to promote repairing mechanisms preserving the host from an exaggerated inflammatory response [6,7,64-66]. Recently, Kalafati et al. demonstrated in vivo that trained neutrophils during granulopoiesis (central trained immunity) promote anti-tumoral effects in a ROSdependent fashion [14,26]. In line with this, our recent published work showed that murine neutrophils primed by gram-negative LPS in vitro display opposing memory-like inflammatory responses, trained sensitivity and tolerance in a dose-response manner [13]. Several studies in other myeloid cells also revealed dose-dependent induction of memory-like inflammatory responses imprinted by LPS $[24,33,34,67]$. However, there have been no studies investigating the role of grampositive LTA-priming in the induction of memory-like inflammatory responses in neutrophils.

The present study firstly describes the role of gram-positive LTA in the induction of mechanisms of immune memory in murine neutrophils. LTA-primed bone marrow neutrophils that have been re-challenged by LPS, displayed a biphasic response, where low-dose LTA priming triggers increased inflammatory responsiveness, and high-dose LTApriming results in tolerance reactions.

To better understand the biological function of these regulatory mechanisms we not only screened for classical pro-inflammatory cytokines such as TNF- $\alpha$ and IL-6, but also addressed associated crucial inflammatory mediators such as ROS and IL-1 $\beta$. Interestingly, levels of IL-6 greatly exceeded TNF- $\alpha$ production, which may be explained by the capacity of endogenous TNF- $\alpha$ to boost IL- 6 production by affecting chromatin modulation of IL-6 regulatory genes [68-70]. Trained neutrophils exhibited enhanced levels of ROS production associated with increased expression of IL-1 $\beta$ enhancing neutrophil recruitment. Contrary, tolerant neutrophils suppress the levels of ROS and IL-1 $\beta$ and supported the release of anti-inflammatory IL-10. In line with these findings, IL-1 cytokines (especially IL-1 $\beta$ ) are known to promote neutrophil recruitment and, together with ROS, to endorse antimicrobial 
defence [71-74]. In a different context, Kalafati et al. outlined the key importance of ROS production by trained neutrophils in vivo displaying anti-tumoral effects [14]. Increased IL-10 levels by tolerant neutrophils are of crucial importance and of dual benefit since IL-10 promotes repairing mechanisms by neutrophils and protects the host against excessive inflammatory reactions [65,71,75-77]. LTA-priming at low doses did not affect IL-10 production which might be due to the lack of B lymphocyte-induced maturation protein-1 (Blimp-1) in vitro, which generally promotes IL-10 production [33]. In should generally be noted that when addressing individual mediators or cytokine networks, it is hard to impossible to replicate in vivo interactions in vitro. This is not an inherent limitation to this study, but it has to be acknowledged that the importance of this novel regulatory mechanism in a living organism remains to be proven.

Several reports have demonstrated the role of pathogen dose provoking opposing memory-like responses in monocytes, macrophages, microglia as well as the hematopoietic stem cells [24,33,34,78,79]. LTA is the main constituent of the cell wall of gram-positive bacteria that acts through its sensing receptor TLR2 driving the downstream activation of NFkB [80]. Although gram-negative LPS and gram-positive LTA act by comparable signalling pathways through the activation of TLRs, they have greater differences between them related to the structural properties that initiate the injury and host responses that follow [81]. Our study reveals similar activation patterns where trained neutrophils express higher levels of TLR2/MyD88 and activation of NFkB-p65, distinct from tolerant neutrophils displaying suppressed levels of the TLR2/MyD88/NFkB-p65 triangle. Previous studies indicate the crucial role of intermediate signalling proteins such as PI3Ks and MAPKs endorsing the development of memory-like responses [13,24,29,67,82,83]. Analogous findings have been reported for the downstream mediator of PI3Ks, Akt, as well as for the Erk1/2 as an important representative of MAPKs family for inflammatory responses.

The essential contribution of TLR/MyD88 pathway induced by microbial agents regulating neutrophil recruitment has been reported previously [84-86]. Our data reveal that trained neutrophils by low-dose LTA-priming exhibiting an increased pro-inflammatory status are characterized by increased migratory activities in vitro. The promigratory state is supported by enhanced levels of CXCL1 as well as by increased expression of CD11a (the $\alpha$ chain of LFA-1). CXCL1 is known to be an important chemokine for host protection by recruiting neutrophils to the site of infection improving also the killing activities, whereas CD11a serves as a key molecule in the neutrophil recruitment cascade [4,87-91]. In contrast, high-dose LTA-primed tolerant neutrophils demonstrated diminished migratory affinities characterized by suppressed levels of CXCL1 and CD11a.

Both, training and tolerance, may serve host protection against bacterial pathogens or against an excessive inflammatory response $[16,92]$. The biological relevance of our finding on the LTA-mediated priming capacity of neutrophils is however not yet clear. There are obvious universal patterns when comparing the effect of LTA and LPS on neutrophil priming and we speculate that there are far more agents that may induce memory-like effects in neutrophils. In the current work we used a cross-over setup with LTA-priming followed by an LPS-hit, suggesting that the level of regulation in priming is rather downstream 
of toll-like receptors. In vivo, immune cells are exposed to large quantities of bacterial metabolites and toxins from the microbiota, especially the gut microbiome. It is therefore possible that a finger print of different bacterial ques may directly modulate neutrophil function and plasticity. Translational deductions need to be drawn with caution, as expression patterns, especially the signalling of cytokine and chemokines are known to greatly differ between species and cell populations [93-95]. Nevertheless, the identification of a novel way to switch between adaptive inflammatory responses may be of interest to the evolving field of adaptive innate immunity.

\section{Conclusions}

Collectively, our data suggest that gram-positive LTA may trigger dose-dependent induction of memory-like responses in murine bone marrow neutrophils in vitro. Low-dose LTA-primed neutrophils trigger trained sensitivity outlined by increased pro-inflammatory mediators, different from tolerant neutrophils marked by diminished proinflammatory reactions and pronounced anti-inflammatory responses. On a cellular level these effects translate to altered neutrophil recruitment in vitro. In light of previous findings at our lab it seems increasingly likely that neutrophils bear limited immune-plasticity and are shaped by their surroundings. The biological relevance of this observation will be the focus of future studies.

Data Availability: The data presented in this study are available on request from the corresponding author upon reasonable request.

Conflicts of Interest: The authors declare that there is no conflict of interest regarding the publication of this paper. The funders had no role in the preparation of the manuscript or in the decision to publish the results.

Authors' Contributions: Trim Lajqi and Hannes Hudalla wrote the manuscript. Trim Lajqi, Maylis Braun, Simon Alexander Kranig and Hannes Hudalla performed the experiments, did the data analysis and interpretations. David Frommhold and Johannes Pöschl reviewed and edited the manuscript. All the authors have read the final manuscript and agree to its publication.

Funding Statement: This work has been developed as a part of the PRIMAL consortium and is funded by the Federal Ministry for Education and Research (Bundesministerium für Bildung und Forschung, BMBF) [01GL1746E to HH, DF].

Acknowledgments: The authors acknowledge Mrs. Britta Heckmann and Ms. Silvia Pezer for skillful technical assistance.

Supplementary Materials: See Supplementary Figure 1 for data on cell viability and cytotoxicity (Supplementary Material).

\section{References}

[1] Rosales, C. Neutrophil: A Cell with Many Roles in Inflammation or Several Cell Types? Front. Physiol., 2018, 9, 113.

[2] Kolaczkowska, E.; Kubes, P. Neutrophil Recruitment and Function in Health and Inflammation. Nat. Rev. Immunol., 2013, 13, 159-175.

[3] Phillipson, M.; Kubes, P. The Neutrophil in Vascular Inflammation. Nat. Med., 2011, 17, 1381-1390.

[4] Ley, K.; Laudanna, C.; Cybulsky, M.I.; Nourshargh, S. Getting to the Site of Inflammation: The Leukocyte Adhesion Cascade Updated. Nat. Rev. Immunol., 2007, 7, 678-689.

[5] Sadik, C.D.; Kim, N.D.; Luster, A.D. Neutrophils Cascading Their Way to Inflammation. Trends Immunol., 2011, 32, 452-460.

[6] Drescher, B.; Bai, F. Neutrophil in Viral Infections, Friend or Foe? Virus Res., 2013, 171, 1-7.

[7] Hidalgo, A.; Chilvers, E.R.; Summers, C.; Koenderman, L. The Neutrophil Life Cycle. Trends Immunol., 2019, 
40, 584-597.

[8] Németh, T.; Sperandio, M.; Mócsai, A. Neutrophils as Emerging Therapeutic Targets. Nat. Rev. Drug Discov., 2020, 19, 253-275.

[9] Hong, C.; Kidani, Y.; A-Gonzalez, N.; Phung, T.; Ito, A.; Rong, X.; Ericson, K.; Mikkola, H.; Beaven, S.W.; Miller, L.S.; Shao, W.H.; Cohen, P.L.; Castrillo, A.; Tontonoz, P.; Bensinger, S.J. Coordinate Regulation of Neutrophil Homeostasis by Liver X Receptors in Mice. J. Clin. Invest., 2012, 122, 337-347.

[10] Shi, J.; Gilbert, G.E.; Kokubo, Y.; Ohashi, T. Role of the Liver in Regulating Numbers of Circulating Neutrophils. Blood, 2001, 98, 1226-1230.

[11] Eash, K.J.; Means, J.M.; White, D.W.; Link, D.C. CXCR4 Is a Key Regulator of Neutrophil Release from the Bone Marrow under Basal and Stress Granulopoiesis Conditions. Blood, 2009, 113, 4711-4719.

[12] Bratton, D.L.; Henson, P.M. Neutrophil Clearance: When the Party Is over, Clean-up Begins. Trends Immunol., 2011, 32, 350-357.

[13] Lajqi, T.; Braun, M.; Kranig, S.A.; Frommhold, D.; Johannes;, P.; Hudalla, H. LPS Induces Opposing Memorylike Inflammatory Responses in Mouse Bone Marrow Neutrophils. Int. J. Mol. Sci., 2021, 22, 9803.

[14] Kalafati, L.; Kourtzelis, I.; Schulte-Schrepping, J.; Li, X.; Hatzioannou, A.; Grinenko, T.; Hagag, E.; Sinha, A.; Has, C.; Dietz, S.; de Jesus Domingues, A.M.; Nati, M.; Sormendi, S.; Neuwirth, A.; Chatzigeorgiou, A.; Ziogas, A.; Lesche, M.; Dahl, A.; Henry, I.; Subramanian, P.; Wielockx, B.; Murray, P.; Mirtschink, P.; Chung, K.J.; Schultze, J.L.; Netea, M.G.; Hajishengallis, G.; Verginis, P.; Mitroulis, I.; Chavakis, T. Innate Immune Training of Granulopoiesis Promotes Anti-Tumor Activity. Cell, 2020, 183, 771-785.

[15] Netea, M.G.; Joosten, L.A.B.; Latz, E.; Mills, K.H.G.; Natoli, G.; Stunnenberg, H.G.; ONeill, L.A.J.; Xavier, R.J. Trained Immunity: A Program of Innate Immune Memory in Health and Disease. Science (80-. )., 2016, 352, aaf1098-aaf1098.

[16] Lajqi, T.; Pöschl, J.; Frommhold, D.; Hudalla, H. The Role of Microbiota in Neutrophil Regulation and Adaptation in Newborns. Front. Immunol., 2020, 11.

[17] Mogensen, T.H. Pathogen Recognition and Inflammatory Signaling in Innate Immune Defenses. Clin. Microbiol. Rev., 2009, 22, 240-273.

[18] Kieser, K.J.; Kagan, J.C. Multi-Receptor Detection of Individual Bacterial Products by the Innate Immune System. Nat. Rev. Immunol., 2017, 17, 376-390.

[19] Takeuchi, O.; Akira, S. Pattern Recognition Receptors and Inflammation. Cell, 2010, 140, 805-820.

[20] Thomas, C.J.; Schroder, K. Pattern Recognition Receptor Function in Neutrophils. Trends Immunol., 2013, 34, 317-328.

[21] Netea, M.G.; van der Meer, J.W.M. Trained Immunity: An Ancient Way of Remembering. Cell Host Microbe, 2017, 21, 297-300.

[22] Novakovic, B.; Habibi, E.; Wang, S.-Y.; Arts, R.J.W.; Davar, R.; Megchelenbrink, W.; Kim, B.; Kuznetsova, T.; Kox, M.; Zwaag, J.; Matarese, F.; van Heeringen, S.J.; Janssen-Megens, E.M.; Sharifi, N.; Wang, C.; Keramati, F.; Schoonenberg, V.; Flicek, P.; Clarke, L.; Pickkers, P.; Heath, S.; Gut, I.; Netea, M.G.; Martens, J.H.A.; Logie, C.; Stunnenberg, H.G. $\beta$-Glucan Reverses the Epigenetic State of LPS-Induced Immunological Tolerance. Cell, 2016, 167, 1354-1368.e14.

[23] Kleinnijenhuis, J.; Quintin, J.; Preijers, F.; Joosten, L.A.B.; Jacobs, C.; Xavier, R.J.; van der Meer, J.W.M.; van Crevel, R.; Netea, M.G. BCG-Induced Trained Immunity in NK Cells: Role for Non-Specific Protection to Infection. Clin. Immunol., 2014, 155, 213-219.

[24] Lajqi, T.; Lang, G.-P.P.; Haas, F.; Williams, D.L.; Hudalla, H.; Bauer, M.; Groth, M.; Wetzker, R.; Bauer, R. Memory-Like Inflammatory Responses of Microglia to Rising Doses of LPS: Key Role of PI3K $\gamma$. Front. Immunol., 2019, 10, 2492.

[25] Jentho, E.; Lajqi, T.; Yang, K.; Winkler, R.; Stojiljkovic, M.; Wetzker, R.; Bauer, M. Pathogen-Induced Hormetic Responses. In The Science of Hormesis in Health and Longevity; Rattan, S.I.S.; Kyriazis, M., Eds.; Elsevier, 2019; pp. 161-170.

[26] Netea, M.G.; Domínguez-Andrés, J.; Barreiro, L.B.; Chavakis, T.; Divangahi, M.; Fuchs, E.; Joosten, L.A.B.; van der Meer, J.W.M.; Mhlanga, M.M.; Mulder, W.J.M.; Riksen, N.P.; Schlitzer, A.; Schultze, J.L.; Stabell Benn, C.; Sun, J.C.; Xavier, R.J.; Latz, E. Defining Trained Immunity and Its Role in Health and Disease. Nat. Rev. Immunol., 2020, 20, 375-388.

[27] Ifrim, D.C.; Quintin, J.; Joosten, L.A.B.; Jacobs, C.; Jansen, T.; Jacobs, L.; Gow, N.A.R.; Williams, D.L.; van der Meer, J.W.M.; Netea, M.G. Trained Immunity or Tolerance: Opposing Functional Programs Induced in Human Monocytes after Engagement of Various Pattern Recognition Receptors. Clin. Vaccine Immunol., 2014, $21,534-545$.

[28] Lajqi, T.; Stojiljkovic, M.; Williams, D.L.; Hudalla, H.; Bauer, M.; Witte, O.W.; Wetzker, R.; Bauer, R.; Schmeer, C. Memory-Like Responses of Brain Microglia Are Controlled by Developmental State and Pathogen Dose. Front. Immunol., 2020, 11, 546415.

[29] Cheng, S.C.; Quintin, J.; Cramer, R.A.; Shepardson, K.M.; Saeed, S.; Kumar, V.; Giamarellos-Bourboulis, E.J.; Martens, J.H.A.; Rao, N.A.; Aghajanirefah, A.; Manjeri, G.R.; Li, Y.; Ifrim, D.C.; Arts, R.J.W.; Van Der Meer, 
B.M.J.W.; Deen, P.M.T.; Logie, C.; O’Neill, L.A.; Willems, P.; Van De Veerdonk, F.L.; Van Der Meer, J.W.M.; $\mathrm{Ng}$, A.; Joosten, L.A.B.; Wijmenga, C.; Stunnenberg, H.G.; Xavier, R.J.; Netea, M.G. MTOR- and HIF-1 $\alpha-$ Mediated Aerobic Glycolysis as Metabolic Basis for Trained Immunity. Science (80-. )., 2014, 345, 1250684.

[30] Netea, M.G.; Latz, E.; Kingston, H.G.; Mills, L.A.; Neill, J.O.'. Innate Immune Memory: A Paradigm Shift in Understanding Host Defense. Nat. Immunol., 2015, 16, 675-679.

[31] Quintin, J.; Saeed, S.; Martens, J.H.A.A.; Giamarellos-Bourboulis, E.J.; Ifrim, D.C.; Logie, C.; Jacobs, L.; Jansen, T.; Kullberg, B.J.; Wijmenga, C.; Joosten, L.A.B.B.; Xavier, R.J.; Van Der Meer, J.W.M.M.; Stunnenberg, H.G.; Netea, M.G. Candida Albicans Infection Affords Protection against Reinfection via Functional Reprogramming of Monocytes. Cell Host Microbe, 2012, 12, 223-232.

[32] Kleinnijenhuis, J.; Quintin, J.; Preijers, F.; Joosten, L.A.B.; Ifrim, D.C.; Saeed, S.; Jacobs, C.; van Loenhout, J.; de Jong, D.; Stunnenberg, H.G.; Xavier, R.J.; van der Meer, J.W.M.; van Crevel, R.; Netea, M.G. Bacille Calmette-Guerin Induces NOD2-Dependent Nonspecific Protection from Reinfection via Epigenetic Reprogramming of Monocytes. Proc. Natl. Acad. Sci., 2012, 109, 17537-17542.

[33] Yuan, R.; Geng, S.; Li, L. Molecular Mechanisms That Underlie the Dynamic Adaptation of Innate Monocyte Memory to Varying Stimulant Strength of TLR Ligands. Front. Immunol., 2016, 7, 497.

[34] Wendeln, A.-C.; Degenhardt, K.; Kaurani, L.; Gertig, M.; Ulas, T.; Jain, G.; Wagner, J.; Häsler, L.M.; Wild, K.; Skodras, A.; Blank, T.; Staszewski, O.; Datta, M.; Centeno, T.P.; Capece, V.; Islam, M.R.; Kerimoglu, C.; Staufenbiel, M.; Schultze, J.L.; Beyer, M.; Prinz, M.; Jucker, M.; Fischer, A.; Neher, J.J. Innate Immune Memory in the Brain Shapes Neurological Disease Hallmarks. Nature, 2018, 556, 332-338.

[35] Morris, M.; Li, L. Molecular Mechanisms and Pathological Consequences of Endotoxin Tolerance and Priming. Arch. Immunol. Ther. Exp. (Warsz)., 2012, 60, 13-18.

[36] Lajqi, T.; Stojiljkovic, M.; Wetzker, R. Toxin-Induced Hormesis May Restrain Aging. Biogerontology, 2019, 20, $1-11$.

[37] Namakula, R.; de Bree, L.C.J.; A. Tvedt, T.H.; Netea, M.G.; Cose, S.; Hanevik, K. Monocytes from Neonates and Adults Have a Similar Capacity to Adapt Their Cytokine Production after Previous Exposure to BCG and $\beta$-Glucan. PLoS One, 2020, 15, e0229287.

[38] Lajqi, T.; Marx, C.; Hudalla, H.; Haas, F.; Große, S.; Wang, Z.Q.; Heller, R.; Bauer, M.; Wetzker, R.; Bauer, R. The Role of the Pathogen Dose and PI3K $\gamma$ in Immunometabolic Reprogramming of Microglia for Innate Immune Memory. Int. J. Mol. Sci., 2021, 22, 2578.

[39] Arts, R.J.W.; Novakovic, B.; ter Horst, R.; Carvalho, A.; Bekkering, S.; Lachmandas, E.; Rodrigues, F.; Silvestre, R.; Cheng, S.C.; Wang, S.Y.; Habibi, E.; Gonçalves, L.G.; Mesquita, I.; Cunha, C.; van Laarhoven, A.; van de Veerdonk, F.L.; Williams, D.L.; van der Meer, J.W.M.; Logie, C.; O’Neill, L.A.; Dinarello, C.A.; Riksen, N.P.; van Crevel, R.; Clish, C.; Notebaart, R.A.; Joosten, L.A.B.; Stunnenberg, H.G.; Xavier, R.J.; Netea, M.G. Glutaminolysis and Fumarate Accumulation Integrate Immunometabolic and Epigenetic Programs in Trained Immunity. Cell Metab., 2016, 24, 807-819.

[40] Arts, R.J.W.; Carvalho, A.; La Rocca, C.; Palma, C.; Rodrigues, F.; Silvestre, R.; Kleinnijenhuis, J.; Lachmandas, E.; Gonçalves, L.G.; Belinha, A.; Cunha, C.; Oosting, M.; Joosten, L.A.B.; Matarese, G.; van Crevel, R.; Netea, M.G. Immunometabolic Pathways in BCG-Induced Trained Immunity. Cell Rep., 2016, 17, 2562-2571.

[41] Domínguez-Andrés, J.; Novakovic, B.; Li, Y.; Scicluna, B.P.; Gresnigt, M.S.; Arts, R.J.W.; Oosting, M.; Moorlag, S.J.C.F.M.; Groh, L.A.; Zwaag, J.; Koch, R.M.; ter Horst, R.; Joosten, L.A.B.; Wijmenga, C.; Michelucci, A.; van der Poll, T.; Kox, M.; Pickkers, P.; Kumar, V.; Stunnenberg, H.; Netea, M.G. The Itaconate Pathway Is a Central Regulatory Node Linking Innate Immune Tolerance and Trained Immunity. Cell Metab., 2019, 29, 211-220.e5.

[42] Ferrante, A. Tumor Necrosis Factor Alpha Potentiates Neutrophil Antimicrobial Activity: Increased Fungicidal Activity against Torulopsis Glabrata and Candida Albicans and Associated Increases in Oxygen Radical Production and Lysosomal Enzyme Release. Infect. Immun., 1989, 57, 2115-2122.

[43] Yektaei-Karin, E.; Moshfegh, A.; Lundahl, J.; Berggren, V.; Hansson, L.-O.; Marchini, G. The Stress of Birth Enhances in Vitro Spontaneous and IL-8-Induced Neutrophil Chemotaxis in the Human Newborn. Pediatr. Allergy Immunol., 2007, 18, 643-651.

[44] Wikoff, W.R.; Anfora, A.T.; Liu, J.; Schultz, P.G.; Lesley, S.A.; Peters, E.C.; Siuzdak, G. Metabolomics Analysis Reveals Large Effects of Gut Microflora on Mammalian Blood Metabolites. Proc. Natl. Acad. Sci. U. S. A., 2009, 106, 3698-3703.

[45] Clarke, T.B.; Davis, K.M.; Lysenko, E.S.; Zhou, A.Y.; Yu, Y.; Weiser, J.N. Recognition of Peptidoglycan from the Microbiota by Nod1 Enhances Systemic Innate Immunity. Nat. Med., 2010, 16, 228-231.

[46] Sridharan, G. V.; Choi, K.; Klemashevich, C.; Wu, C.; Prabakaran, D.; Pan, L. Bin; Steinmeyer, S.; Mueller, C.; Yousofshahi, M.; Alaniz, R.C.; Lee, K.; Jayaraman, A. Prediction and Quantification of Bioactive Microbiota Metabolites in the Mouse Gut. Nat. Commun., 2014, 5, 5492.

[47] Moorlag, S.J.C.F.M.; Rodriguez-Rosales, Y.A.; Gillard, J.; Fanucchi, S.; Theunissen, K.; Novakovic, B.; de Bont, C.M.; Negishi, Y.; Fok, E.T.; Kalafati, L.; Verginis, P.; Mourits, V.P.; Koeken, V.A.C.M.; de Bree, L.C.J.; Pruijn, G.J.M.; Fenwick, C.; van Crevel, R.; Joosten, L.A.B.; Joosten, I.; Koenen, H.; Mhlanga, M.M.; Diavatopoulos, D.A.; Chavakis, T.; Netea, M.G. BCG Vaccination Induces Long-Term Functional Reprogramming of Human 
Neutrophils. Cell Rep., 2020, 33, 108387.

[48] Percy, M.G.; Gründling, A. Lipoteichoic Acid Synthesis and Function in Gram-Positive Bacteria. Annu. Rev. Microbiol., 2014, 68, 81-100.

[49] Ginsburg, I. Role of Lipoteichoic Acid in Infection and Inflammation. Lancet Infect. Dis., 2002, 2, $171-179$.

[50] Lotz, S.; Aga, E.; Wilde, I.; van Zandbergen, G.; Hartung, T.; Solbach, W.; Laskay, T. Highly Purified Lipoteichoic Acid Activates Neutrophil Granulocytes and Delays Their Spontaneous Apoptosis via CD14 and TLR2. J. Leukoc. Biol., 2004, 75, 467-477.

[51] Schymeinsky, J.; Sindrilaru, A.; Frommhold, D.; Sperandio, M.; Gerstl, R.; Then, C.; Mócsai, A.; ScharffetterKochanek, K.; Walzog, B. The Vav Binding Site of the Non-Receptor Tyrosine Kinase Syk at Tyr 348 Is Critical for B2 Integrin (CD11/CD18)-Mediated Neutrophil Migration. Blood, 2006, 108, 3919-3927.

[52] Roberts, R.L.; Gallin, J.I. Rapid Method for Isolation of Normal Human Peripheral Blood Eosinophils on Discontinuous Percoll Gradients and Comparison with Neutrophils. Blood, 1985, 65, 433-440.

[53] Malik, M.; Jividen, K.; Padmakumar, V.C.; Cataisson, C.; Li, L.; Lee, J.; Howard, O.M.Z.; Yuspa, S.H. Inducible NOS-Induced Chloride Intracellular Channel 4 (CLIC4) Nuclear Translocation Regulates Macrophage Deactivation. Proc. Natl. Acad. Sci. U. S. A., 2012, 109, 6130-6135.

[54] Frommhold, D.; Kamphues, A.; Hepper, I.; Pruenster, M.; Lukić, I.K.; Socher, I.; Zablotskaya, V.; Buschmann, K.; Lange-Sperandio, B.; Schymeinsky, J.; Ryschich, E.; Poeschl, J.; Kupatt, C.; Nawroth, P.P.; Moser, M.; Walzog, B.; Bierhaus, A.; Sperandio, M. RAGE and ICAM-1 Cooperate in Mediating Leukocyte Recruitment during Acute Inflammation in Vivo. Blood, 2010, 116, 841-849.

[55] Rio, D.C.; Ares, M.; Hannon, G.J.; Nilsen, T.W. Purification of RNA Using TRIzol (TRI Reagent). Cold Spring Harb. Protoc., 2010, pdb.prot5439.

[56] Schmittgen, T.D.; Livak, K.J. Analyzing Real-Time PCR Data by the Comparative CT Method. Nat. Protoc., 2008, 3, 1101-1108.

[57] Saeed, S.; Quintin, J.; Kerstens, H.H.D.; Rao, N.A.; Aghajanirefah, A.; Matarese, F.; Cheng, S.C.; Ratter, J.; Berentsem, K.; Van Der Ent, M.A.; Sharifi, N.; Jamssern-Megens, E.M.; Ter Huurne, M.; Mandoli, A.; Van Schaik, T.; Ng, A.; Burden, F.; Downes, K.; Frontini, M.; Kumar, V.; Giamarellos-Bourboulis, E.J.; Ouwehand, W.H.; Van Der Meer, J.W.M.; Joosten, L.A.B.; Wijmenga, C.; Martens, J.H.A.; Xavier, R.J.; Logie, C.; Netea, M.G.; Stunnenberg, H.G. Epigenetic Programming of Monocyte-to-Macrophage Differentiation and Trained Innate Immunity. Science (80-. )., 2014, 345, 1251086.

[58] Chen, X.; El Gazzar, M.; Yoza, B.K.; McCall, C.E. The NF-KB Factor RelB and Histone H3 Lysine Methyltransferase G9a Directly Interact to Generate Epigenetic Silencing in Endotoxin Tolerance. J. Biol. Chem., 2009, 284, 27857-27865.

[59] Milite, C.; Feoli, A.; Viviano, M.; Rescigno, D.; Cianciulli, A.; Balzano, A.L.; Mai, A.; Castellano, S.; Sbardella, G. The Emerging Role of Lysine Methyltransferase SETD8 in Human Diseases. Clin. Epigenetics, 2016, 8, 102.

[60] Zhou, X.Y.; Gao, R.; Hu, J.; Gao, D.P.; Liao, Y.L.; Yang, J.J. Trained Innate Immunity by Repeated Low-Dose Lipopolysaccharide Injections Displays Long-Term Neuroprotective Effects. Mediators Inflamm., 2020, 2020, 8191079.

[61] Tercan, H.; Riksen, N.P.; Joosten, L.A.B.; Netea, M.G.; Bekkering, S. Trained Immunity: Long-Term Adaptation in Innate Immune Responses. Arterioscler. Thromb. Vasc. Biol., 2021, 41, 55-61.

[62] Domínguez-Andrés, J.; Arts, R.J.W.; Bekkering, S.; Bahrar, H.; Blok, B.A.; de Bree, L.C.J.; Bruno, M.; Bulut, Ö.; Debisarun, P.A.; Dijkstra, H.; Cristina dos Santos, J.; Ferreira, A. V.; Flores-Gomez, D.; Groh, L.A.; Grondman, I.; Helder, L.; Jacobs, C.; Jacobs, L.; Jansen, T.; Kilic, G.; Klück, V.; Koeken, V.A.C.M.; Lemmers, H.; Moorlag, S.J.C.F.M.; Mourits, V.P.; van Puffelen, J.H.; Rabold, K.; Röring, R.J.; Rosati, D.; Tercan, H.; van Tuijl, J.; Quintin, J.; van Crevel, R.; Riksen, N.P.; Joosten, L.A.B.; Netea, M.G. In Vitro Induction of Trained Immunity in Adherent Human Monocytes. STAR Protoc., 2021, 2, 100365.

[63] Gollwitzer, E.S.; Marsland, B.J. Impact of Early-Life Exposures on Immune Maturation and Susceptibility to Disease. Trends Immunol., 2015, 36, 684-696.

[64] Kaplan, M.J.; Radic, M. Neutrophil Extracellular Traps: Double-Edged Swords of Innate Immunity. J. Immunol., 2012, 189, 2689-2695.

[65] Akdis, C.A.; Akdis, M. Mechanisms of Immune Tolerance to Allergens: Role of IL-10 and Tregs. J. Clin. Invest., 2014, 124, 4678-4680.

[66] Zhang, X.; Majlessi, L.; Deriaud, E.; Leclerc, C.; Lo-Man, R. Coactivation of Syk Kinase and MyD88 Adaptor Protein Pathways by Bacteria Promotes Regulatory Properties of Neutrophils. Immunity, 2009, 31, 761-771.

[67] Morris, M.C.; Gilliam, E.A.; Button, J.; Li, L. Dynamic Modulation of Innate Immune Response by Varying Dosages of Lipopolysaccharide (LPS) in Human Monocytic Cells. J. Biol. Chem., 2014, 289, 21584-21590.

[68] Zimmermann, M.; Aguilera, F.B.; Castellucci, M.; Rossato, M.; Costa, S.; Lunardi, C.; Ostuni, R.; Girolomoni, G.; Natoli, G.; Bazzoni, F.; Tamassia, N.; Cassatella, M.A. Chromatin Remodelling and Autocrine TNF $\alpha$ Are Required for Optimal Interleukin-6 Expression in Activated Human Neutrophils. Nat. Commun., 2015, 6, 6061.

[69] Fong, Y.; Tracey, K.J.; Moldawer, L.L.; Hesse, D.G.; Manogue, K.B.; Kenney, J.S.; Lee, A.T.; Kuo, G.C.; Allison, A.C.; Lowry, S.F.; Cerami, A. Antibodies to Cachectin/Tumor Necrosis Factor Reduce Interleukin $1 \beta$ and 
Interleukin 6 Appearance during Lethal Bacteremia. J. Exp. Med., 1989, 170, 1627-1633.

[70] Benihoud, K.; Esselin, S.; Descamps, D.; Jullienne, B.; Salone, B.; Bobé, P.; Bonardelle, D.; Connault, E.; Opolon, P.; Saggio, I.; Perricaudet, M. Respective Roles of TNF- $\alpha$ and IL-6 in the Immune Response-Elicited by Adenovirus-Mediated Gene Transfer in Mice. Gene Ther., 2007, 14, 533-544.

[71] Mantovani, A.; Cassatella, M.A.; Costantini, C.; Jaillon, S. Neutrophils in the Activation and Regulation of Innate and Adaptive Immunity. Nat. Rev. Immunol., 2011, 11, 519-531.

[72] Hsu, L.C.; Enzler, T.; Seita, J.; Timmer, A.M.; Lee, C.Y.; Lai, T.Y.; Yu, G.Y.; Lai, L.C.; Temkin, V.; Sinzig, U.; Aung, T.; Nizet, V.; Weissman, I.L.; Karin, M. IL-1 $\beta$-Driven Neutrophilia Preserves Antibacterial Defense in the Absence of the Kinase IKK $\beta$. Nat. Immunol., 2011, 12, 144-150.

[73] Miller, L.S.; Pietras, E.M.; Uricchio, L.H.; Hirano, K.; Rao, S.; Lin, H.; O’Connell, R.M.; Iwakura, Y.; Cheung, A.L.; Cheng, G.; Modlin, R.L. Inflammasome-Mediated Production of IL-1 $\beta$ Is Required for Neutrophil Recruitment against Staphylococcus Aureus in Vivo. J. Immunol., 2008, 179, 6933-6942.

[74] Jorgensen, I.; Lopez, J.P.; Laufer, S.A.; Miao, E.A. IL-1 $\beta$, IL-18, and Eicosanoids Promote Neutrophil Recruitment to Pore-Induced Intracellular Traps Following Pyroptosis. Eur. J. Immunol., 2016, 46, 2761-2766.

[75] Borregaard, N. Neutrophils, from Marrow to Microbes. Immunity, 2010, 33, 657-670.

[76] Nathan, C. Neutrophils and Immunity: Challenges and Opportunities. Nat. Rev. Immunol., 2006, 6, $173-182$.

[77] Peñaloza, H.F.; Nieto, P.A.; Muñoz-Durango, N.; Salazar-Echegarai, F.J.; Torres, J.; Parga, M.J.; AlvarezLobos, M.; Riedel, C.A.; Kalergis, A.M.; Bueno, S.M. Interleukin-10 Plays a Key Role in the Modulation of Neutrophils Recruitment and Lung Inflammation during Infection by Streptococcus Pneumoniae. Immunology, 2015, 146, 100-112.

[78] de Laval, B.; Maurizio, J.; Kandalla, P.K.; Brisou, G.; Simonnet, L.; Huber, C.; Gimenez, G.; Matcovitch-Natan, O.; Reinhardt, S.; David, E.; Mildner, A.; Leutz, A.; Nadel, B.; Bordi, C.; Amit, I.; Sarrazin, S.; Sieweke, M.H. $\mathrm{C} / \mathrm{EBP} \beta$-Dependent Epigenetic Memory Induces Trained Immunity in Hematopoietic Stem Cells. Cell Stem Cell, 2020, 26, 657-674.e8.

[79] Schaafsma, W.; Zhang, X.; van Zomeren, K.C.; Jacobs, S.; Georgieva, P.B.; Wolf, S.A.; Kettenmann, H.; Janova, H.; Saiepour, N.; Hanisch, U.K.; Meerlo, P.; van den Elsen, P.J.; Brouwer, N.; Boddeke, H.W.G.M.; Eggen, B.J.L. Long-Lasting pro-Inflammatory Suppression of Microglia by LPS-Preconditioning Is Mediated by RelBDependent Epigenetic Silencing. Brain. Behav. Immun., 2015, 48, 205-221.

[80] Ellingsen, E.; Morath, S.; Flo, T.; Schromm, A.; Hartung, T.; Thiemermann, C.; Espevik, T.; Golenbock, D.; Foster, D.; Solberg, R.; Aasen, A.; Wang, J. Induction of Cytokine Production in Human T Cells and Monocytes by Highly Purified Lipoteichoic Acid: Involvement of Toll-like Receptors and CD14. Med. Sci. Monit., 2002, 8, BR149-56.

[81] Cohen, J. Mechanisms of Tissue Injury in Sepsis: Contrasts between Gram Positive and Gram Negative Infection. J. Chemother., 2001, 1, 153-158.

[82] Maitra, U.; Gan, L.; Chang, S.; Li, L. Low-Dose Endotoxin Induces Inflammation by Selectively Removing Nuclear Receptors and Activating CCAAT/Enhancer-Binding Protein Delta. J Immunol, 2011, 186, 4467-4473.

[83] Maitra, U.; Deng, H.; Glaros, T.; Baker, B.; Capelluto, D.G.S.; Li, Z.; Li, L. Molecular Mechanisms Responsible for the Selective and Low-Grade Induction of Proinflammatory Mediators in Murine Macrophages by Lipopolysaccharide. J. Immunol., 2012, 189, 1014-1023.

[84] Zhang, D.; Chen, G.; Manwani, D.; Mortha, A.; Xu, C.; Faith, J.J.; Burk, R.D.; Kunisaki, Y.; Jang, J.-E.; Scheiermann, C.; Merad, M.; Frenette, P.S. Neutrophil Ageing Is Regulated by the Microbiome. Nature, 2015, $525,528-532$.

[85] Deshmukh, H.S.; Liu, Y.; Menkiti, O.R.; Mei, J.; Dai, N.; O’Leary, C.E.; Oliver, P.M.; Kolls, J.K.; Weiser, J.N.; Worthen, G.S. The Microbiota Regulates Neutrophil Homeostasis and Host Resistance to Escherichia Coli K1 Sepsis in Neonatal Mice. Nat. Med., 2014, 20, 524-530.

[86] Balmer, M.L.; Schürch, C.M.; Saito, Y.; Geuking, M.B.; Li, H.; Cuenca, M.; Kovtonyuk, L. V.; McCoy, K.D.; Hapfelmeier, S.; Ochsenbein, A.F.; Manz, M.G.; Slack, E.; Macpherson, A.J. Microbiota-Derived Compounds Drive Steady-State Granulopoiesis via MyD88/TICAM Signaling. J. Immunol., 2014, 193, 5273-5283.

[87] Sawant, K. V.; Poluri, K.M.; Dutta, A.K.; Sepuru, K.M.; Troshkina, A.; Garofalo, R.P.; Rajarathnam, K. Chemokine CXCL1 Mediated Neutrophil Recruitment: Role of Glycosaminoglycan Interactions. Sci. Rep., 2016, 6, 33123.

[88] Lefort, C.T.; Ley, K. Neutrophil Arrest by LFA-1 Activation. Front. Immunol., 2012, 3, 157.

[89] Hudalla, H.; Karenberg, K.; Kuon, R.-J.; Pöschl, J.; Tschada, R.; Frommhold, D. LPS-Induced Maternal Inflammation Promotes Fetal Leukocyte Recruitment and Prenatal Organ Infiltration in Mice. Pediatr. Res., 2018, 84, 757-764.

[90] Kranig, S.A.; Lajqi, T.; Tschada, R.; Braun, M.; Kuss, N.; Pöschl, J.; Hudalla, H. Leukocyte Infiltration of Cremaster Muscle in Mice Assessed by Intravital Microscopy. J. Vis. Exp., 2020.

[91] Fitterer, R.; Lajqi, T.; Kranig, S.A.; Braun, M.; Theissig, N.; Kuss, N.; Pöschl, J.; Frommhold, D.; Hudalla, H. LArginine Modulates Neonatal Leukocyte Recruitment in a Gestational Age-Dependent Manner. J. Clin. Med., 2020, 9, 2772. 
[92] Bauer, M.; Weis, S.; Netea, M.G.; Wetzker, R. Remembering Pathogen Dose: Long-Term Adaptation in Innate Immunity. Trends Immunol., 2018, 39, 438-445.

[93] Hagai, T.; Chen, X.; Miragaia, R.J.; Rostom, R.; Gomes, T.; Kunowska, N.; Henriksson, J.; Park, J.E.; Proserpio, V.; Donati, G.; Bossini-Castillo, L.; Vieira Braga, F.A.; Naamati, G.; Fletcher, J.; Stephenson, E.; Vegh, P.; Trynka, G.; Kondova, I.; Dennis, M.; Haniffa, M.; Nourmohammad, A.; Lässig, M.; Teichmann, S.A. Gene Expression Variability across Cells and Species Shapes Innate Immunity. Nature, 2018, 563, 197-202.

[94] Mestas, J.; Hughes, C.C.W. Of Mice and Not Men: Differences between Mouse and Human Immunology. J. Immunol., 2004, 172, 2731-2738.

[95] Zschaler, J.; Schlorke, D.; Arnhold, J. Differences in Innate Immune Response between Man and Mouse. Crit. Rev. Immunol., 2014, 34, 433-454. 